\title{
Plasticity of upper thermal limits to acute and chronic temperature variation in Manduca sexta larvae
}

\author{
Joel G. Kingsolver ${ }^{\ddagger}$, Heidi J. MacLean*, Silvan B. Goddin and Kate E. Augustine
}

\begin{abstract}
In many ectotherms, exposure to high temperatures can improve subsequent tolerance to higher temperatures. However, the differential effects of single, repeated or continuous exposure to high temperatures are less clear. We measured the effects of single heat shocks and of diurnally fluctuating or constant rearing temperatures on the critical thermal maximum $\left(\mathrm{CT}_{\max }\right)$ for final instar larvae of Manduca sexta. Brief $(2 \mathrm{~h})$ heat shocks at temperatures of $35^{\circ} \mathrm{C}$ and above significantly increased $\mathrm{CT}_{\max }$ relative to control temperatures $\left(25^{\circ} \mathrm{C}\right)$. Increasing mean temperatures (from 25 to $30^{\circ} \mathrm{C}$ ) or greater diurnal fluctuations (from constant to $\pm 10^{\circ} \mathrm{C}$ ) during larval development also significantly increased $\mathrm{CT}_{\max }$. Combining these data showed that repeated or continuous temperature exposure during development improved heat tolerance beyond the effects of a single exposure to the same maximum temperature. These results suggest that both acute and chronic temperature exposure can result in adaptive plasticity of upper thermal limits.
\end{abstract}

KEY WORDS: Acclimation, Heat tolerance, Heat shock, Temperature exposure, Critical thermal maximum

\section{INTRODUCTION}

Temporal variation in natural environments is ubiquitous. Aspects of this variation are often predictable, making phenotypic plasticity an important mechanism by which organisms adapt to variable environments. Photoperiod, temperature and precipitation often serve as environmental cues that induce phenotypically plastic changes and improve organismal fitness in subsequent weather and climatic conditions (Tauber and Tauber, 1976). The time scales of environmental cues and of plastic responses are important factors that influence the reliability of cues for predicting future environmental conditions and the fitness consequences of plasticity (Levins, 1968; Moran, 1992). For example, some forms of developmental plasticity can reduce or even reverse the adaptive value of plasticity because of the time lag between detection of environmental cues and phenotypic expression (Kingsolver and Huey, 1998).

Physiological acclimation to temperature variation is a form of phenotypic plasticity found in many ectotherms. Acclimation may occur over a range of time scales. For example, acute, brief (1-2 h) exposure to high (or low) temperatures can increase subsequent tolerance to heat (or cold) in a wide variety of organisms (Angilletta, 2009). In many cases, such heat shocks induce the production of heat shock proteins (HSPs), which act as chaperones to protect key

Department of Biology, University of North Carolina, Chapel Hill, NC 27599, USA. *Present address: Institute for Bioscience, Aarhus University, Aarhus C 8000.

${ }^{\ddagger}$ Author for correspondence ( jgking@bio.unc.edu)

Received 29 January 2016; Accepted 24 February 2016 proteins and improve tolerance and survival during subsequent heat exposure (Hofmann, 1999; Kregel, 2002; Hoffmann et al., 2003). In the absence of additional heat shocks, heat tolerance typically declines to baseline levels within a few days (Dahlgaard et al., 1998; Bahrndorff et al., 2009; Karl et al., 2012).

Chronic exposure to constant, increased temperatures can also improve performance at higher temperatures (Hoffmann et al., 2003; Zerebecki and Sorte, 2011), but chronic exposure to stressfully high temperatures can reduce tolerance, growth rates and survival (Chown and Terblanche, 2007; Angilletta, 2009). More recently, several studies have examined the effects of diurnal temperature fluctuation on acclimation of physiological traits. For example, diurnal temperature fluctuations increase heat tolerance and HSP70 synthesis in woodlice, fruit flies and zebrafish (Schaefer and Ryan, 2006; Bozinovic et al., 2011; Folguera et al., 2011), and increase growth rate, developmental rate and heat tolerance in butterflies (Fischer et al., 2011). In these studies, it is usually not clear whether increased heat tolerance is the result of exposure to a maximum daily temperature, as opposed to effects of diurnal fluctuations per se. For example, does increased tolerance result from exposure to a single high-temperature event, to repeated events over several days, or to chronic exposure to increased temperatures throughout a life stage? The answer is relevant to understanding the differing responses of ectotherms to extreme events, heat waves and climate warming.

Here, we addressed this question by examining upper thermal limits (critical thermal maximum, $\mathrm{CT}_{\max }$ ) for the larvae of Manduca sexta. A Manduca larva can experience a wide range of diurnal fluctuations and body temperatures during its larval life (Casey, 1976; Kingsolver et al., 2012; Woods, 2013), and repeated daily exposure to body temperatures above $35-38^{\circ} \mathrm{C}$ throughout larval development can reduce growth and survival rates (Kingsolver et al., 2015). Manduca sexta larvae also strongly increase HSP70 production in response to acute heat shocks of $38-44^{\circ} \mathrm{C}$ (Fittinghoff and Riddiford, 1990), and brief (30 $\mathrm{min}$ ) exposure to temperatures above $44-45^{\circ} \mathrm{C}$ greatly increases larval mortality (Casey, 1976).

We conducted two sets of experiments. First, we used single, brief heat shocks to determine how heat shock temperature affects upper thermal limits. Second, we used constant and fluctuating rearing conditions to determine how mean temperature and diurnal temperature fluctuations throughout larval development affect upper thermal limits. We combined the data from these experiments to test whether single, repeated and continuous exposure to high temperatures have different effects on acclimation of upper thermal limits.

\section{MATERIALS AND METHODS} Study system: Manduca sexta $L$.

Our studies used larvae from our laboratory colony of $M$. sexta maintained at the University of North Carolina Chapel Hill (Kingsolver, 2007; Kingsolver and Nagle, 2007; Kingsolver et al., 
2009; Diamond and Kingsolver, 2010, 2012). This lab colony was originally derived from field collections near Raleigh, NC, USA, in the 1960s, and has been maintained on standard artificial diet at constant $\left(25-26^{\circ} \mathrm{C}\right)$ temperature for over 300 generations (Kingsolver, 2007; Kingsolver and Nagle, 2007). Previous studies show that larvae from this colony have reduced survival rates at constant rearing temperatures of $35^{\circ} \mathrm{C}$, relative to larvae from field populations in southeastern USA (Kingsolver and Nagle, 2007). However, lab and field populations of M. sexta have similar growth, development and survival responses to diurnal fluctuations during larval development (Kingsolver et al., 2009).

\section{Measuring upper thermal limits: $\mathbf{C T}_{\max }$}

Heat tolerance was determined using a ramping temperature assay to measure failure time and $\mathrm{CT}_{\max }$ (Terblanche et al., 2007; Overgaard et al., 2012), defined as the temperature at which a larva begins to twitch or lose muscular control. We used a starting temperature of $38^{\circ}$ $\mathrm{C}$ (with a $12 \mathrm{~min}$ acclimation period) and a ramping rate of $0.25^{\circ}$ $\mathrm{C}$ min $^{-1}$ (Terblanche et al., 2007) using a programmable water bath (Thermo Scientific with AC-200 controller). Newly hatched larvae were reared in their treatment conditions (see below) until molt into the 5th (last) instar. During the morning of day 2 in the 5 th instar, each larva was placed on filter paper at the bottom of a covered, weighted $1000 \mathrm{ml}$ glass beaker, which was then placed into the water bath. Larvae from multiple treatment groups were measured during each ramping assay. Following the acclimation period, larvae were monitored once every minute until failure (began to twitch or lose muscular control) was observed. The time to failure and the temperature of the water bath at that time were then recorded for each larva. We note that $\mathrm{CT}_{\max }$ is not a direct measure of mortality: nearly all larvae survived to pupation, when returned to control conditions following the $\mathrm{CT}_{\max }$ assay (J.G.K., H.J.M., S.B.G. and K.E.A., unpublished results). However, loss of muscular control in the field can cause $M$. sexta larvae to fall off of their host plant, increasing the risk of mortality Casey (1976).

\section{Experiments: acute and developmental treatments Acute (heat shock) experiment}

Larvae were reared from hatching in a constant temperature of $25^{\circ} \mathrm{C}$ and a $14 \mathrm{~h}$ light: $10 \mathrm{~h}$ dark photocycle until molt into the 5th larval instar. On the first day of the 5th instar, larvae were weighed, placed in an environmental chamber without food, and subjected to a $2 \mathrm{~h}$ heat shock from 13:00 h to 15:00 h EDT, at one of seven different heat shock temperatures: 25 (control), 30, 32, 35, 38, 40 or $42^{\circ} \mathrm{C}$. Following the heat shock, larvae were returned to their rearing conditions of $25^{\circ} \mathrm{C}$. The morning of the next day ( 2 nd day of 5 th instar), heat tolerance of each larva was measured as described above. During each assay, larvae from both the control $\left(25^{\circ} \mathrm{C}\right)$ group and one or two other heat shock treatment groups were measured. Sample sizes for the treatment groups were: $N=28\left(25^{\circ} \mathrm{C}\right), N=3$ $\left(30^{\circ} \mathrm{C}\right), N=15\left(32^{\circ} \mathrm{C}\right), N=10\left(35^{\circ} \mathrm{C}\right), N=10\left(38^{\circ} \mathrm{C}\right), N=17\left(40^{\circ} \mathrm{C}\right)$ and $N=10\left(42^{\circ} \mathrm{C}\right)$.

\section{Developmental (rearing temperature) experiment}

This experiment used a full-factorial experimental design with two factors: mean temperature (MT), with three treatment levels $(25,28$ and $30^{\circ} \mathrm{C}$ ); and diurnal temperature fluctuations (DTF), with two treatment levels $\left[ \pm 0^{\circ} \mathrm{C}\right.$ (constant), and $\left.\pm 10^{\circ} \mathrm{C}\right]$. A $14 \mathrm{~h}$ light: $10 \mathrm{~h}$ dark photocycle was maintained in all treatments. The $\pm 10^{\circ} \mathrm{C}$ treatment group experienced a diurnal temperature cycle with $2 \mathrm{~h}$ at the maximum temperature (13:00-15:00 $\mathrm{h}$ EDT) and $2 \mathrm{~h}$ at the minimum temperature (01:00-03:00 EDT), with linear ramping between these temperatures (see Fig. 1). Newly hatched larvae were assigned randomly to each of the treatment groups, and reared until molt into the 5 th instar. On the morning of the 2 nd day of the 5 th instar, heat tolerance of each larva was measured as described above. During each assay, larvae from both the $\pm 0^{\circ} \mathrm{C}$ and $\pm 10^{\circ} \mathrm{C}$ treatment groups for a given mean temperature were measured. Sample sizes were $N=77$ for the $\pm 0^{\circ} \mathrm{C}$ and $N=81$ for the $\pm 10^{\circ} \mathrm{C}$ treatment groups.

\section{Statistical analyses}

All statistical analyses were performed using fixed-effects linear models in $\mathrm{R}$ (version 3.0.1). We used $\mathrm{CT}_{\max }$ as the response variable in all analyses. Using failure time as the response variable gave qualitatively identical results in terms of significance testing. For analyses of the single heat shock experiment, heat shock temperature was considered as a continuous covariate; similar results were obtained when heat shock temperature was considered as a categorical factor. For analyses of the rearing temperature experiment, mean temperature and diurnal temperature range were considered as fixed (categorical) factors. Visual inspection of residuals was used to confirm that assumptions of normality and homogeneity of variance were met (Zuur et al., 2009).

In our two experiments, larvae in the different treatment groups differed both in the maximum temperature experienced during acclimation (i.e. prior to measurement of $\mathrm{CT}_{\max }$ ) and in the duration and temporal pattern of temperature exposure to maximum temperature (Fig. 1). For example, in the $\pm 0^{\circ} \mathrm{C}$ rearing treatments, larvae were exposed continuously throughout larval development to a constant temperature; the maximum temperature experienced equaled the mean temperature (Fig. 1). Larvae in the $\pm 10^{\circ} \mathrm{C}$ treatments repeatedly experienced a daily high temperature throughout their development, and the maximum temperature experienced was $10^{\circ} \mathrm{C}$ above the mean temperature (Fig. 1). Larvae in the heat shock treatment briefly experienced a maximum temperature (equal to the heat shock temperature) a single time, the day prior to measurement. By combining data from the two experiments, we can distinguish the effects of maximum temperature experienced and the type of exposure to maximum temperature: single $=$ acute heat shock treatment; repeated $= \pm 10^{\circ} \mathrm{C}$ diurnal temperature fluctuations throughout larval development; continuous $=$ constant rearing temperature throughout larval

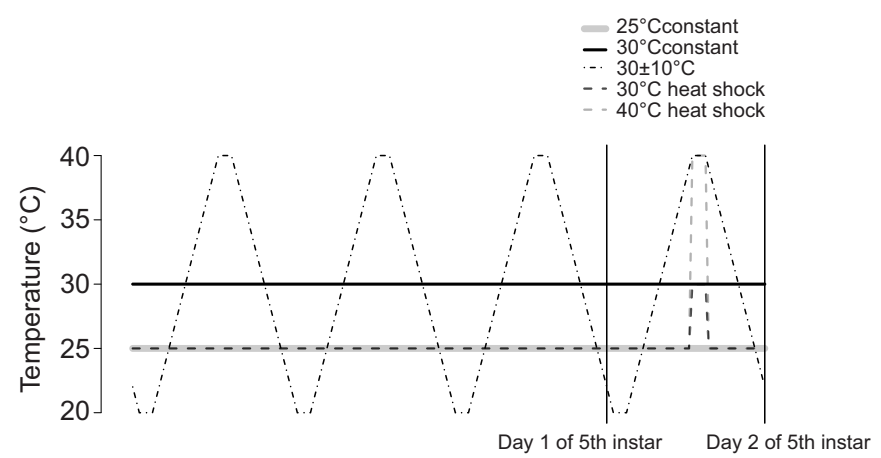

Fig. 1. Temperature as a function of time experienced by larvae for representative treatments in the heat shock and rearing temperature experiments. Five treatment groups are represented: 30 and $40^{\circ} \mathrm{C}$ heat shock (HS) treatments; $30 \pm 10^{\circ} \mathrm{C}$ diurnally fluctuating rearing treatment; and 25 and $30^{\circ} \mathrm{C}$ constant $\left( \pm 0^{\circ} \mathrm{C}\right)$ rearing treatments. Note that prior to measurement of the critical thermal maximum ( $\mathrm{CT}_{\text {max }}$; on day 2 of the 5 th instar), the maximum temperature experienced was the same for Manduca sexta larvae in the $30^{\circ} \mathrm{C}$ heat shock and the $30^{\circ} \mathrm{C}$ constant rearing treatments $\left(=30^{\circ} \mathrm{C}\right)$, and for larvae in the $40^{\circ} \mathrm{C}$ heat shock and the $30 \pm 10^{\circ} \mathrm{C}$ rearing treatments $\left(=40^{\circ} \mathrm{C}\right)$. See Materials and methods. 


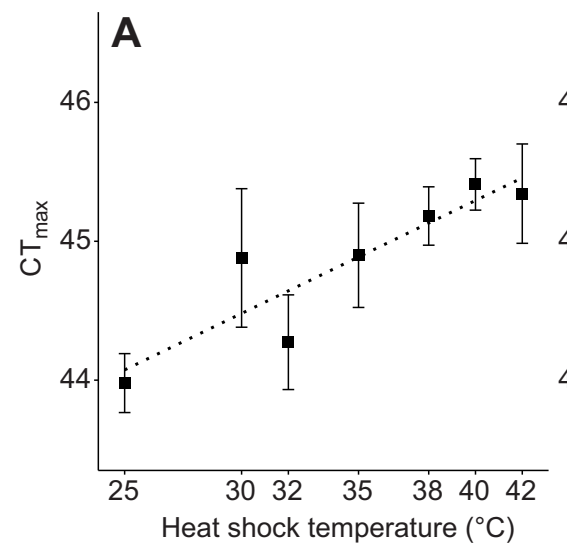

B

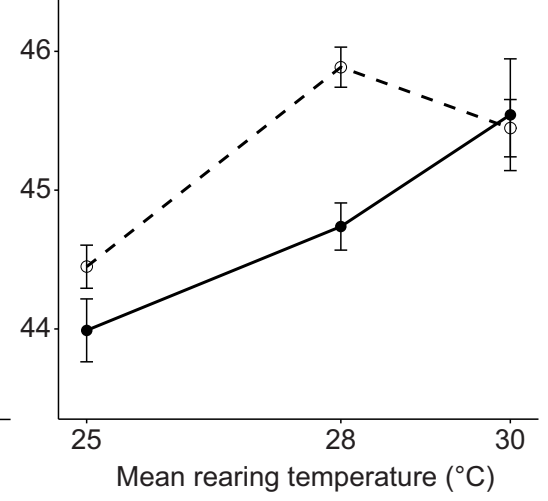

Fig. 2. $C T_{\max }$ as a function of temperature in the heat shock and rearing temperature experiments. (A) Acute heat shock experiment. The linear regression line (dotted) is also indicated. (B) Rearing temperature experiment. Filled circles, solid line: $\pm 0^{\circ} \mathrm{C}$ diurnal temperature range (constant); open circles, dashed line: $\pm 10^{\circ} \mathrm{C}$ diurnal temperature range. In each case, mean ( \pm 1 s.e.m.) $\mathrm{CT}_{\text {max }}$ is shown for 5 th instar M. sexta larvae. development. The analysis considered maximum temperature as a continuous covariate and type of exposure (single, repeated, continuous) as a factor. We report the $P$-values based on the ANOVA for each analysis in the text.

\section{RESULTS AND DISCUSSION}

Single, brief heat shocks significantly increased $\mathrm{CT}_{\max }(P<0.001)$. Heat shock temperatures of $35^{\circ} \mathrm{C}$ produced increases in mean $\mathrm{CT}_{\max }$ (Fig. 2A). We note that the $30^{\circ} \mathrm{C}$ heat shock treatment only had a sample size of $N=3$, much smaller than all other treatment groups $(N=10-28)$.

The rearing temperature experiment showed that mean temperature $(P<0.001)$, diurnal temperature range $(P<0.001)$ and their interaction $(P=0.047)$ all had significant effects on $\mathrm{CT}_{\max }$. Increasing mean temperature increased mean $\mathrm{CT}_{\text {max }}$, and diurnal fluctuations increased mean $\mathrm{CT}_{\max }$ at lower $\left(<30^{\circ} \mathrm{C}\right)$ mean temperatures (Fig. 2B).

Combining the data from these experiments revealed that maximum temperature significantly increased $\mathrm{CT}_{\max }(P<0.001)$ in

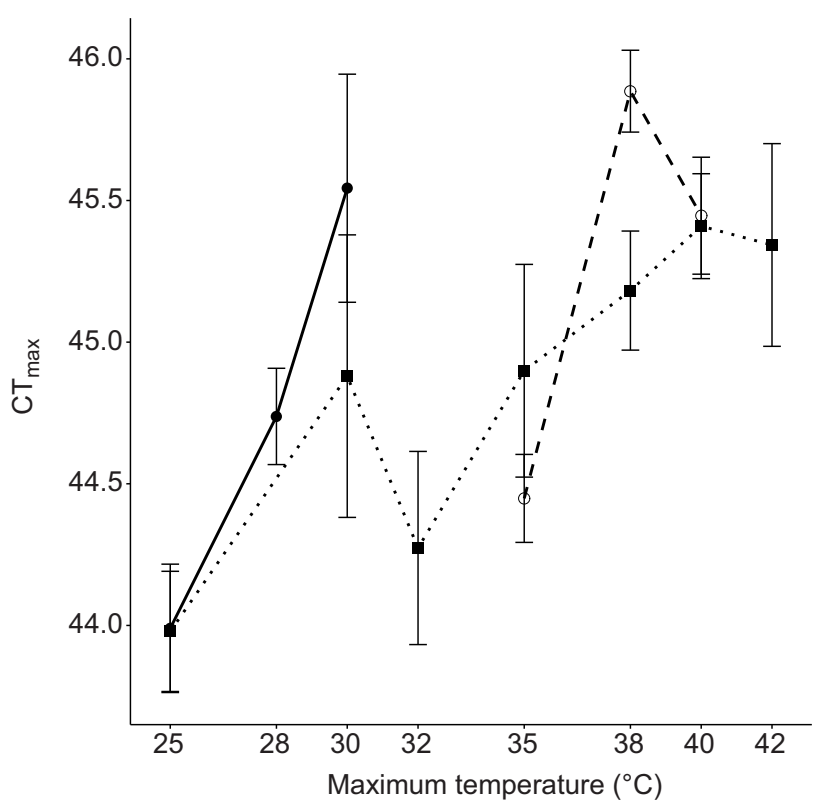

Fig. 3. $\mathrm{CT}_{\max }$ as a function of maximum temperature in the heat shock and rearing temperature experiments. Filled squares, dotted trend line: single heat shock; open circles, dashed line: diurnally fluctuating temperature; and filled circles, solid line: continuous constant temperature. Mean ( \pm 1 s.e.m.) $\mathrm{CT}_{\max }$ is shown for 5th instar M. sexta larvae. See Materials and methods and Fig. 1. both experiments (Fig. 3). The type of experimental exposure and its interaction with maximum temperature also significantly affected $\mathrm{CT}_{\text {max }}(P<0.001$ for each): higher constant temperatures and larger diurnal fluctuations increased mean $\mathrm{CT}_{\max }$ beyond the effect of maximum temperature alone (Fig. 3). These results suggest that both high temperatures and the pattern of exposure to those temperatures during development can alter heat tolerance.

Increased heat tolerance in response to a brief, recent heat shock (sometimes called heat-hardening) is a common form of physiological acclimation in insects and other ectotherms (Hofmann, 1999; Kregel, 2002). Our results for M. sexta suggest that heat-hardening may occur at relatively low temperatures: mean $\mathrm{CT}_{\max }$ was increased by heat shocks of $35^{\circ} \mathrm{C}$ (Fig. 2). In the field, late-instar M. sexta larvae routinely exceed body temperatures of $35^{\circ} \mathrm{C}$ or more during midday conditions in summer, and temperatures above $40^{\circ} \mathrm{C}$ are not uncommon (Casey, 1976; Kingsolver et al., 2012; Woods, 2013). This suggests that environmental conditions that increase heat tolerance are commonplace in this species, resulting in acclimation to seasonal changes in environmental temperatures. This pattern may be widespread: organisms in highly variable thermal environments, including terrestrial insects and intertidal invertebrates, frequently mount HSP responses within the range of body temperatures normally experienced in the field (Hofmann, 1999; Dahlhoff and Rank, 2007; Tomanek, 2010).

Acclimation to different constant developmental temperatures has been widely observed in fish, insects and other ectotherms, although plastic changes in heat tolerance appear less substantial than in cold tolerance (Chown and Terblanche, 2007; Fischer et al., 2010; Overgaard et al., 2011; Seebacher et al., 2014). Fewer studies have explored physiological acclimation of heat tolerance to diurnal fluctuations in temperature (Hutchison and Michael, 1970; Hokanson et al., 1977; Podrabsky and Somero, 2004; Colinet et al., 2015). For example, in Drosophila melanogaster, diurnal fluctuations $\left( \pm 5^{\circ} \mathrm{C}\right)$ increased heat tolerance (measured as recovery time from heat coma) of adults, especially at higher mean temperatures (Bozinovic et al., 2011). Heat tolerance (heat knockdown recovery time) of adult Lycaena butterflies was greater when larvae were reared at high mean temperatures and with diurnal temperature fluctuations (Fischer et al., 2011). In adult Mediterranean fruit flies, increasing diurnal fluctuations for 10 days strongly increased $\mathrm{CT}_{\max }$, whereas increasing mean temperatures had little effect (Terblanche et al., 2010). Schaefer and Ryan (2006) showed that diurnal fluctuations in temperature during acclimation increased heat tolerance $\left(\mathrm{CT}_{\max }\right)$ of zebrafish, at least at lower mean temperatures. Our results for $M$. sexta larvae parallel those for 
zebrafish: mean $\mathrm{CT}_{\max }$ increased at higher mean developmental temperatures, and diurnal fluctuations increased mean $\mathrm{CT}_{\max }$ at lower $\left(25\right.$ and $\left.28^{\circ} \mathrm{C}\right)$ but not higher $\left(30^{\circ} \mathrm{C}\right)$ mean temperatures (Fig. 2B). As suggested by Schaefer and Ryan (2006), the interactive effects of mean temperature and temperature fluctuation on heat tolerance may emerge because at high mean temperatures, diurnal fluctuations can generate stressfully high temperatures. Recent studies of growth rate in $M$. sexta support this interpretation. For example, at a mean temperature of $25^{\circ} \mathrm{C}$, diurnal fluctuations $\left( \pm 10^{\circ} \mathrm{C}\right)$ during larval development increase maximal growth rates and the optimal temperature for growth for 5 th instar larvae, revealing beneficial acclimation to diurnal fluctuations (Kingsolver et al., 2015). By contrast, at a mean temperature of $30^{\circ} \mathrm{C}$, increasing diurnal fluctuations during development strongly reduces rates of growth, development and survival (Kingsolver et al., 2015).

Of course, diurnal fluctuations also increase the maximum and minimum daily temperatures experienced by organisms (Marshall and Sinclair, 2012; Colinet et al., 2015). Do high temperatures experienced throughout development increase $\mathrm{CT}_{\max }$ beyond the effects of a single, short-term exposure? By combining the results from our heat shock and rearing temperature experiments, our analyses suggest that changes in heat tolerance are strongly determined by maximum temperature (Fig. 3), whether the maximum temperature is experienced once (acute heat shock treatments), repeatedly every day (diurnally fluctuating treatments) or continuously throughout development (constant temperature treatments). However, rearing temperatures also have additional effects beyond maximal temperature: both repeated and chronic exposure to high temperatures during development significantly altered $\mathrm{CT}_{\max }$ (Fig. 3).

Because our experimental treatments include exposure to increased temperature throughout larval development, our treatments differ in both the number and total duration of exposure to 'stressful' temperatures. Our study demonstrates that developmental acclimation to higher maximum temperature increases heat tolerance beyond that due to a single, short-term heat shock. Recent studies of cold tolerance of overwintering insect larvae suggest that the number, intensity and duration of cold exposure can have differing effects on tolerance and other traits (Sinclair and Chown, 2005; Marshall and Sinclair, 2012; Colinet et al., 2015). For example, in overwintering larvae of eastern spruce budworm, the number of cold exposures, rather than the intensity or duration of exposure, determines tolerance and survival to cold (Marshall and Sinclair, 2015). These experiments involve exposure within a single larval instar (2nd), and do not consider effects across development. Tolerance may also vary with age and development stage. For example, cold tolerance of adult female $D$. melanogaster declines rapidly with age, presumably as a result of senescence (Colinet et al., 2013). In our study, we standardized our measurements for individuals in the same developmental stage (2nd day of the 5th instar); because developmental temperatures alter rates of larval development, these individuals necessarily vary in chronological age.

The increases in $\mathrm{CT}_{\max }$ due to acclimation that we observed are relatively modest: only $1-2^{\circ} \mathrm{C}$ above the mean control value $\left(44.0^{\circ} \mathrm{C}\right)$. However, in many parts of its range in Central America and southern USA, body temperatures of $M$. sexta larvae in the field can often approach these temperatures (Casey, 1976; Kingsolver et al., 2012; Woods, 2013). For example, Woods (2013) estimated that in suitable habitat for this species in southwestern USA and northern Mexico, 5th instar larvae experience maximal body temperatures above $44.3^{\circ} \mathrm{C}$ in $29 \%$ of the area; but maximal temperatures above $46^{\circ} \mathrm{C}$ are much more restricted (Woods, 2013). Casey (1976) found that 3rd instar $M$. sexta larvae from southwestern USA could survive a $30 \mathrm{~min}$ exposure to $44^{\circ} \mathrm{C}$, but there was $100 \%$ mortality at $46^{\circ} \mathrm{C}$. Thus, even small increases in $\mathrm{CT}_{\text {max }}$ could be important in reducing or avoiding heat stress and mortality.

\section{Acknowledgements}

We thank Sarah Diamond, Jessica Higgins, Art Woods and an anonymous reviewer for suggestions on previous drafts of the manuscript.

\section{Competing interests}

The authors declare no competing or financial interests.

\section{Author contributions}

J.G.K. conceived and designed the experiments; H.J.M. set up the measurement apparatus and protocols; S.B.G., H.J.M. and K.E.A. performed the experiments; J.G.K. performed the statistical analyses; K.E.A. created the figures; J.G.K., H.J.M. and K.E.A. drafted and revised the manuscript.

\section{Funding}

This research was supported in part by the US National Science Foundation [IOS1120500 to J.G.K.].

\section{References}

Angilletta, M. J. (2009). Thermal Adaptation: A Theoretical and Empirical Synthesis. Oxford: Oxford University Press.

Bahrndorff, S., Mariën, J., Loeschcke, V. and Ellers, J. (2009). Dynamics of heatinduced thermal stress resistance and Hsp70 expression in the springtail, Orchesella cincta. Funct. Ecol. 23, 233-239.

Bozinovic, F., Bastías, D. A., Boher, F., Clavijo-Baquet, S., Estay, S. A. and Angilletta, M. J. (2011). The mean and variance of environmental temperature interact to determine physiological tolerance and fitness. Physiol. Biochem. Zool. 84, 543-552.

Casey, T. M. (1976). Activity patterns, body temperature and thermal ecology in two desert caterpillars (Lepidoptera: Sphingidae). Ecology 57, 485-497.

Chown, S. L. and Terblanche, J. S. (2007). Physiological diversity in insects: ecological and evolutionary contexts. Adv. Insect Physiol. 33, 50-152.

Colinet, H., Siaussat, D., Bozzolan, F. and Bowler, K. (2013). Rapid decline of cold tolerance at young age is associated with expression of stress genes in Drosophila melanogaster. J. Exp. Biol. 216, 253-259.

Colinet, H., Sinclair, B. J., Vernon, P. and Renault, D. (2015). Insects in fluctuating thermal environments. Annu. Rev. Entomol. 60, 123-140.

Dahlgaard, J., Loeschcke, V., Michalak, P. and Justesen, J. (1998). Induced thermotolerance and associated expression of the heat-shock protein Hsp70 in adult Drosophila melanogaster. Funct. Ecol. 12, 786-793.

Dahlhoff, E. P. and Rank, N. E. (2007). The role of stress proteins in responses of a montane willow leaf beetle to environmental temperature variation. J. Biosci. 32 , 477-488.

Diamond, S. E. and Kingsolver, J. G. (2010). Environmental dependence of thermal reaction norms: host plant quality can reverse the temperature-size rule. Am. Nat. 175, 1-10.

Diamond, S. E. and Kingsolver, J. G. (2012). Host plant adaptation and the evolution of thermal reaction norms. Oecologia 169, 353-360.

Fischer, K., Dierks, A., Franke, K., Geister, T. L., Liszka, M., Winter, S. and Pflicke, C. (2010). Environmental effects on temperature stress resistance in the tropical butterfly Bicyclus anynana. PLoS ONE 5, e15284.

Fischer, K., Kölzow, N., Höltje, H. and Karl, I. (2011). Assay conditions in laboratory experiments: is the use of constant rather than fluctuating temperatures justified when investigating temperature-induced plasticity? Oecologia 166, 23-33.

Fittinghoff, C. M. and Riddiford, L. M. (1990). Heat sensitivity and protein synthesis during heat-shock in the tobacco hornworm, Manduca sexta. J. Comp. Physiol. B 160, 346-356.

Folguera, G., Bastías, D. A., Caers, J., Rojas, J. M., Piulachs, M.-D., Bellés, X. and Bozinovic, F. (2011). An experimental test of the role of environmental temperature variability on ectotherm molecular, physiological and life-history traits: implications for global warming. Comp. Biochem. Physiol. A Mol. Integr. Physiol. 159, 242-246.

Hoffmann, A. A., Sørensen, J. G. and Loeschcke, V. (2003). Adaptation of Drosophila to temperature extremes: bringing together quantitative and molecular approaches. J. Therm. Biol. 28, 175-216.

Hofmann, G. E. (1999). Ecologically relevant variation in induction and function of heat shock proteins in marine organisms. Am. Zool. 39, 889-900. 
Hokanson, K. E. F., Kleiner, C. F. and Thorslund, T. W. (1977). Effects of constant temperatures and diel temperature fluctuations on specific growth and mortality rates and yield of Juvenile Rainbow Trout, Salmo gairdneri. J. Fish. Res. Board Can. 34, 639-648.

Hutchison, V. H. and Michael, R. F. (1970). Thermal tolerances of Rana pipiens acclimated to daily temperature cycles. Herpetologica 26, 1-8.

Karl, I., Michalowsky, C., Sørensen, J. G., Loeschcke, V. and Fischer, K. (2012). Effects of rearing and induction temperature on the temporal dynamics of heat shock protein 70 expression in a butterfly. Physiol. Entomol. 37, 103-108.

Kingsolver, J. G. (2007). Variation in growth and instar number in field and laboratory Manduca sexta. Proc. R. Soc. B Biol. Sci. 274, 977-981.

Kingsolver, J. G. and Huey, R. B. (1998). Evolutionary analyses of morphological and physiological plasticity in thermally variable environments. Am. Zool. $\mathbf{3 8}$, 545-560.

Kingsolver, J. G. and Nagle, A. M. (2007). Evolutionary divergence in thermal sensitivity and diapause of field and laboratory populations of Manduca sexta. Physiol. Biochem. Zool. 80, 473-479.

Kingsolver, J. G., Ragland, G. J. and Diamond, S. E. (2009). Evolution in a constant environment: thermal fluctuations and thermal sensitivity of laboratory and field populations of Manduca sexta. Evolution 63, 537-541.

Kingsolver, J. G., Diamond, S. E., Seiter, S. A. and Higgins, J. K. (2012). Direct and indirect phenotypic selection on developmental trajectories in Manduca sexta. Funct. Ecol. 26, 598-607.

Kingsolver, J. G., Higgins, J. K. and Augustine, K. (2015). Fluctuating temperatures and ectotherm growth: distinguishing non-linear and timedependent effects. J. Exp. Biol. 218, 2218-2225.

Kregel, K. C. (2002). Heat shock proteins: modifying factors in physiological stress responses and acquired thermotolerance. J. Appl. Physiol. 92, 2177-2186.

Levins, R. (1968). Evolution in Changing Environments. Princeton, NJ: Princeton U Press.

Marshall, K. E. and Sinclair, B. J. (2012). The impacts of repeated cold exposure on insects. J. Exp. Biol. 215, 1607-1613..

Marshall, K. E. and Sinclair, B. J. (2015). The relative importance of number, duration and intensity of cold stress events in determining survival and energetics of an overwintering insect. Funct. Ecol. 29, 357-366.

Moran, N. A. (1992). The evolutionary maintenance of alternative phenotypes. Am. Nat. 139, 971-989.
Overgaard, J., Kristensen, T. N., Mitchell, K. A. and Hoffmann, A. A. (2011) Thermal tolerance in widespread and tropical Drosophila species: does phenotypic plasticity increase with latitude? Am. Nat. 178, S80-S96.

Overgaard, J., Kristensen, T. N. and Sørensen, J. G. (2012). Validity of thermal ramping assays used to assess thermal tolerance in arthropods. PLoS ONE 7, e32758.

Podrabsky, J. E. and Somero, G. N. (2004). Changes in gene expression associated with acclimation to constant temperatures and fluctuating daily temperatures in an annual killifish Austrofundulus limnaeus. J. Exp. Biol. 207, 2237-2254.

Schaefer, J. and Ryan, A. (2006). Developmental plasticity in the thermal tolerance of zebrafish Danio rerio. J. Fish Biol. 69, 722-734.

Seebacher, F., White, C. R. and Franklin, C. E. (2014). Physiological plasticity increases resilience of ectothermic animals to climate change. Nat. Clim. Change 5, 61-66.

Sinclair, B. J. and Chown, S. L. (2005). Deleterious effects of repeated cold exposure in a freeze-tolerant sub-Antarctic caterpillar. J. Exp. Biol. 208, 869-879.

Tauber, M. J. and Tauber, C. A. (1976). Insect seasonality: diapause maintenance, termination, and postdiapause development. Ann. Rev. Entomol. 21, 81-107.

Terblanche, J. S., Deere, J. A., Clusella-Trullas, S., Janion, C. and Chown, S. L. (2007). Critical thermal limits depend on methodological context. Proc. R. Soc. B Biol. Sci. 274, 2935-2943.

Terblanche, J. S., Nyamukondiwa, C. and Kleynhans, E. (2010). Thermal variability alters climatic stress resistance and plastic responses in a globally invasive pest, the Mediterranean fruit fly (Ceratitis capitata). Entomol. Exp. Appl. 137, 304-315.

Tomanek, L. (2010). Variation in the heat shock response and its implication for predicting the effect of global climate change on species' biogeographical distribution ranges and metabolic costs. J. Exp. Biol. 213, 971-979.

Woods, H. A. (2013). Ontogenetic changes in the body temperature of an insect herbivore. Funct. Ecol. 27, 1322-1331.

Zerebecki, R. A. and Sorte, C. J. (2011). Temperature tolerance and stress proteins as mechanisms of invasive species success. PLoS ONE 6, e14806-e14812.

Zuur, A. F., leno, E. N., Walker, N. J., Saveliev, A. A. and Smith, G. M. (2009) Miexed Effects Models and Extensions in Ecology with R. New York: Springer. 